\title{
Finding zones of stress concentrations and seismic events in deep ore mining affected by high horizontal stresses
}

V.A. Eremenko Institute of Mining, Siberian Branch, Russian Academy of Sciences, Russia

A.A. Eremenko Institute of Mining, Siberian Branch, Russian Academy of Sciences, Russia

L.N. Gakhova Institute of Mining, Siberian Branch, Russian Academy of Sciences, Russia

I.V. Klishin Institute of Mining, Siberian Branch, Russian Academy of Sciences, Russia

\section{Abstract}

Based on the analytical investigation with math modelling and field research using various rock stressstrain state assessment techniques, the authors revealed mechanisms of stress and seismic event concentration zones in rocks during ore extraction.

\section{Introduction}

In order to successfully and intelligently control stresses in rocks, mining engineers require an unbiased and user-friendly tool for evaluating and forecasting the variable geotechnical situation at any stage of mining. The authors discuss this issue in reference to an iron ore mine located in West Siberia, where mining is carried out at $1050 \mathrm{~m}$ below surface, and is affected by tectonic and induced stresses in damaged rocks (Eremenko et al., 2008). Local horizontal stresses exceed vertical stresses by a factor of 1.3-2.6 outside the zone of the extraction influence, and by a factor of 3.5-5.2 inside the influence zone as illustrated in Figure 1 (Safe Mining Guide, 1991; Petukhov and Batugina, 1999).

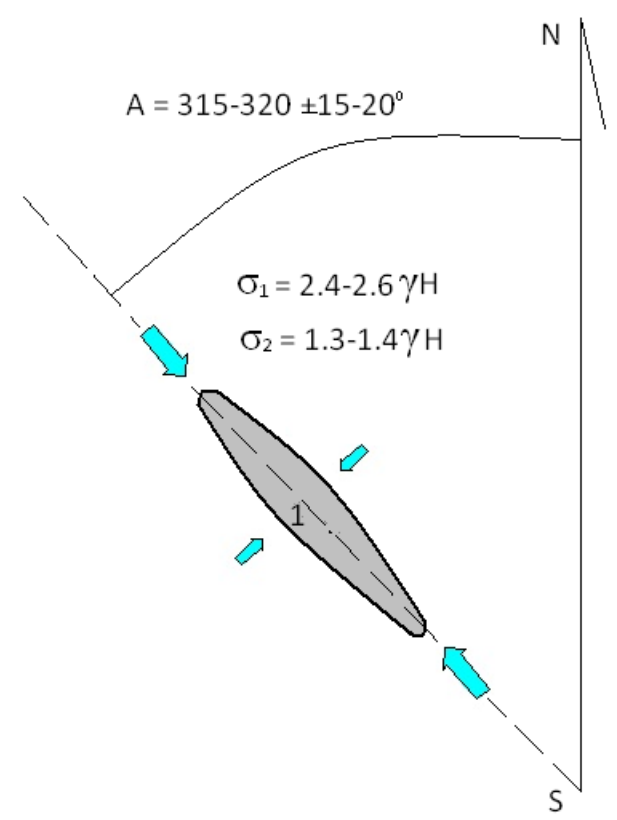

(a)

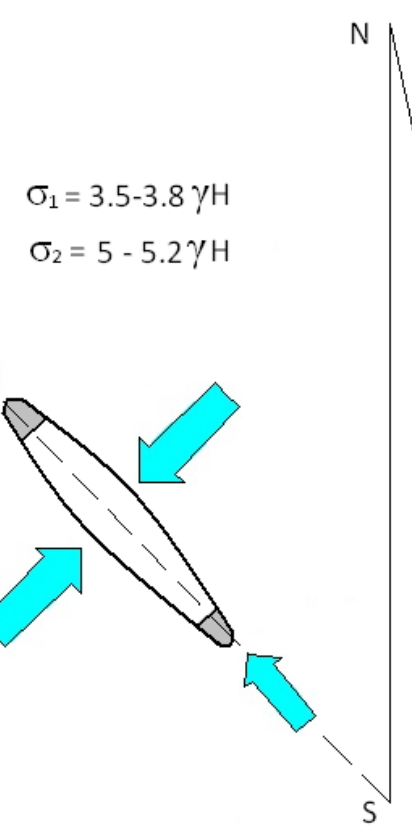

(b)

Figure 1 Principal stresses $\sigma 1$ and $\sigma 2$ outside (a) and inside (b) the impact zone of the extraction. 
1-represents the orebody; and A-the azimuth of the maximum in situ compressive stress, $r$-the bulk weight of the overlying strata; H-the actual mining depth

One of the widely used extraction methods is sublevel caving where the void is filled with caved host rock (Figure 2). Blasting severely affects the rock mass. In West Siberia, small-scale blasting (0.7-20 t of explosive) and large-scale blasting (120 to $370 \mathrm{t}$ of explosives) results in caving of 30,000 to $250,000 \mathrm{~m}^{3}$ of rocks.

Seismic events are mostly recorded in the active stoping areas and at the bottom blocks adjacent to goafs, where many development headings are located. These dynamic events have seismic energies ranging from 10 to $10^{9} \mathrm{~J}$ and cause rockbursts of greater than $10 \mathrm{~m}^{3}$ in capacity, which results in breakage or damage of lining, displacement of mining machines and equipment, and disrupts the extraction process.

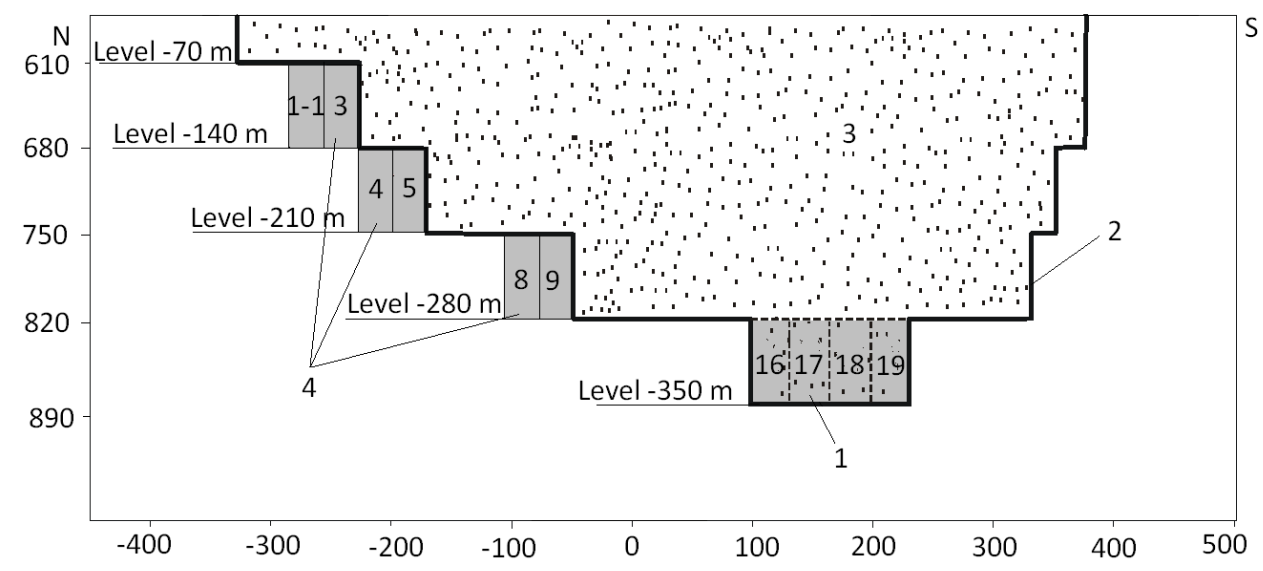

Figure 2 Schematic illustration of actual extraction at one of the mining districts of the Tashtagol iron ore mine (profile along the orebody strike). 1-uncovering blocks; 2boundary of mined-out space;

3-mined-out space; 4-extraction blocks (1-1 to 19 are numbers of the extraction blocks)

\section{Analytical and experimental findings on the location of stress concentrations and seismic events}

Analysis of the numerical modelling results allowed the localisation of concentrated horizontal stress zones versus the length-to-height ratio of mined-out space, as well as against the horizontal components of stresses, $\lambda$ (Figure 3 ).

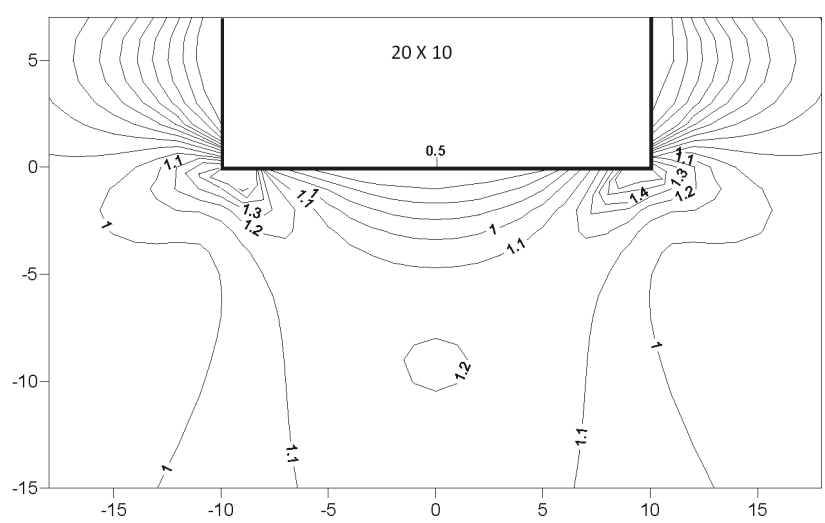

(a)

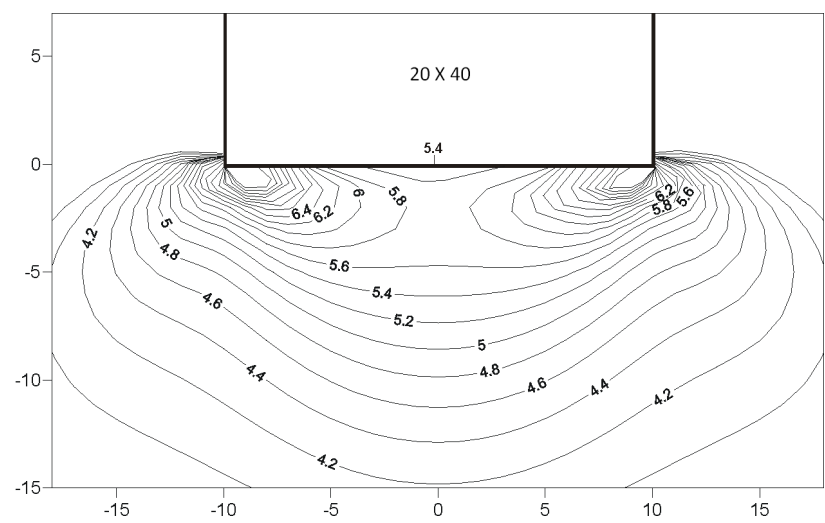

(b)

Figure 3 Distribution of induced stresses around the mined-out void for different ratios of stress: a) $20 \mathrm{~m}$ long $\times 10 \mathrm{~m} \mathrm{high} \mathrm{goaf} \mathrm{and} \lambda=1$; b) $20 \times 40 \mathrm{~m}$-length/height of the goaf and $\lambda=3$ 


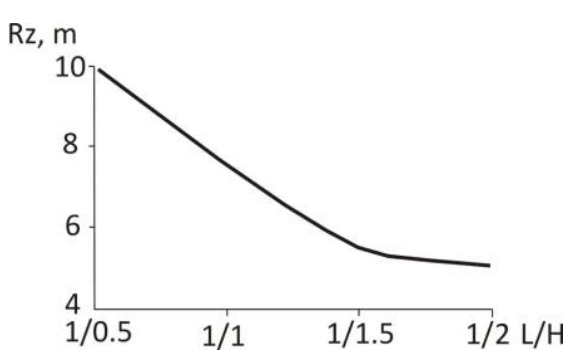

(a)

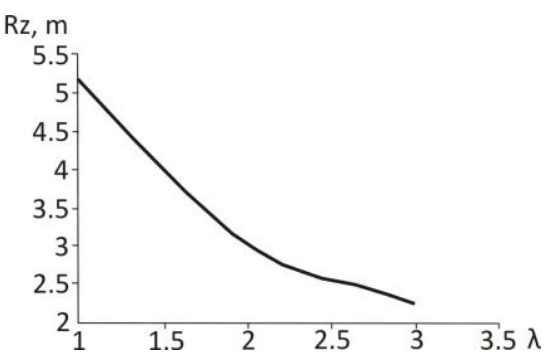

(b)

Figure 4 Location of the maximal horizontal stress zone, Rz, versus (a) the length/height ratio of the mined out void, $\mathrm{L} / \mathrm{H}$, and (b) coefficient of horizontal component of stresses, $\lambda$

It has been found that in higher stopes (increased from $20 \times 10 \mathrm{~m}$ to $20 \times 40 \mathrm{~m}$ as shown in Figure $4 \mathrm{a}$ ), as well as with the higher coefficient of the horizontal component of stresses, $\lambda$, from 1 to 3 (Figure 4b), the zone of the maximal horizontal stresses moves closer to the goaf bottom and the stress concentration factor increases. The stress concentration factor also changes with depth inside the rock mass, not only with varying length-to-height ratios of the mined-out voids, but also under different stress environments (Figures $5 a$ and $5 b$ ).

The modelling results on stresses and their concentration zones are confirmed with the field research of the stress-strain state in rocks. The maximum stress zone and their association with clusters of seismic events were determined based on electrometry and microseismic detections. Stresses were assessed from core disking and relieve slot making (Petukhov and Zaprygaev, 1975).

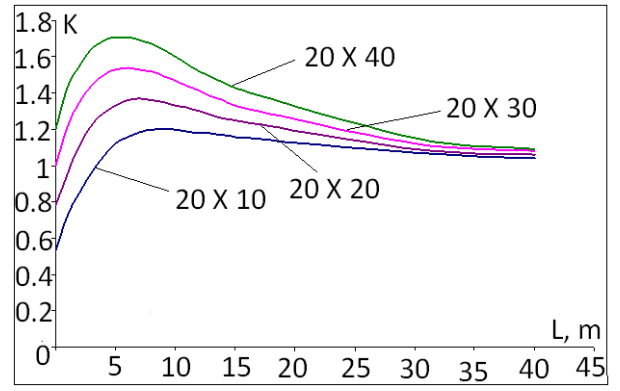

(a)

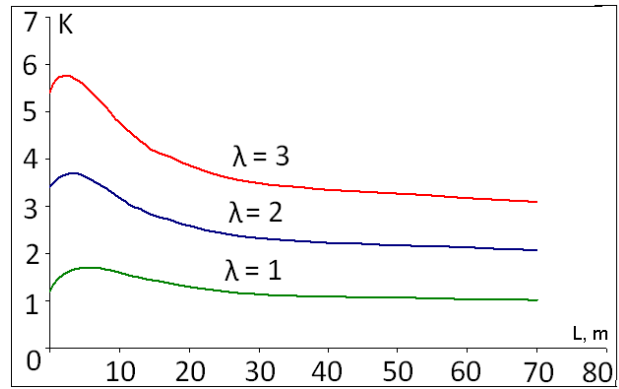

(b)

Figure 5 Variation in the stress concentration coefficient $K$ (determined as the ratio of the measured stresses to in situ stresses) with depth into the intact rock mass, D, for (a) different $L / H$ of mined out voids and (b) different coefficients of horizontal component of stresses, $\lambda$, and the $20 \times 40 \mathrm{~m}$ goaf

The authors have found regularities in the concentration zones of horizontal stresses and seismic events in rocks during sublevel ore caving (Figure 6). In the top-down mining of steep orebodies, considering the orebody thickness, as well as the internal friction and cohesion of rocks, the maximal stress zones occur 20 to $70 \mathrm{~m}$ below the bottom of the operational level. Empirically, the occurrence of the maximum horizontal stress can be expressed as:

$$
\mathrm{Rz}=\mathrm{T}\left(1.174-\frac{0.00033 \mathrm{C} \cos \varphi}{1-\sin \varphi}\right)
$$

where $\mathrm{Rz}$-is the maximal stress zone location (in $\mathrm{m}$ ); $\mathrm{T}$-is the thickness of the orebody (in $\mathrm{m}$ ); C-is the rock cohesion (in $\mathrm{MPa}$ ); $\varphi$-is the internal friction angle (in degrees). 


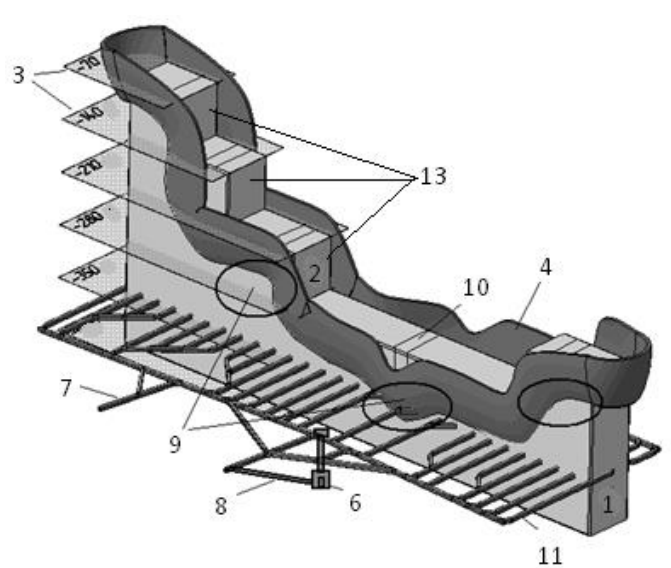

(a)

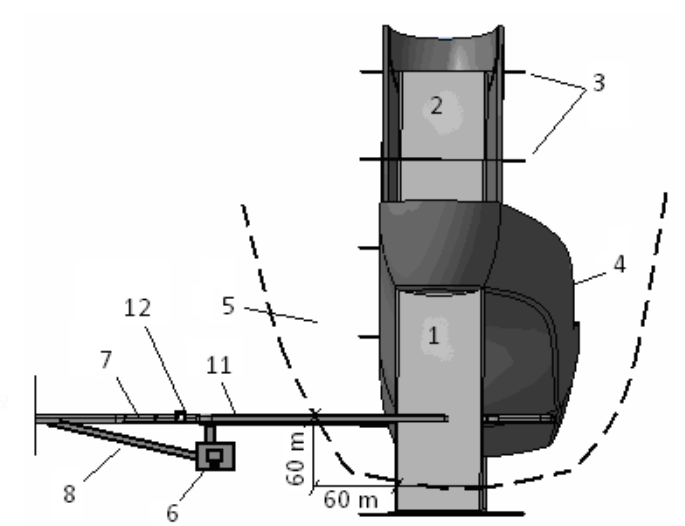

(b)

Figure 6 Top-down extraction with the induced block caving technique and the location ore crushers. The perspective view is (a) and side view is (b). 1-orebody with dip angle 70 to $90^{\circ} ; 2-$ extraction blocks; 3-extraction levels; 4-zone of maximal stresses; 5-zone of increased stress concentration; 6-crusher cell; 7-offset; 8-conveyor roadway; 9-zones of concentrated seismic events; 10-uncovering of the lower-lying level; 11-crossdrift; 12cross-strata heading;

13-boundary of the mined-out space

If several levels are being mined concurrently, the Rz relative to the first extracted level can be expressed as:

$$
\mathrm{Rz}=\mathrm{H}(\mathrm{n}-1)+\mathrm{T}\left(1.174-\frac{0.00033 \mathrm{C} \cos \varphi}{1-\sin \varphi}\right)
$$

where $\mathrm{H}$ is the height of a level (in $\mathrm{m}$ ); and $\mathrm{n}$ is the levels extracted.

Formation of the stress concentration zones follows complex patterns both in space and in time, since orebody extraction proceeds on a number of levels concurrently, and can be advanced from the sides to the centre of the orebody, and, from the centre toward the sides. In the beginning of ore extraction on a new level, or in the uncovering blocks, the stress concentration zone is at a depth of $30 \mathrm{~m}$ under the bottom of the extraction level. As the extraction advances, the stress concentration zone shifts to 60-70 m, below the extraction level. The relationship between the occurrence of the maximal stress zone and the width of the stoping front in a level where 1 to 30 blocks are being extracted is shown in Figure 7.

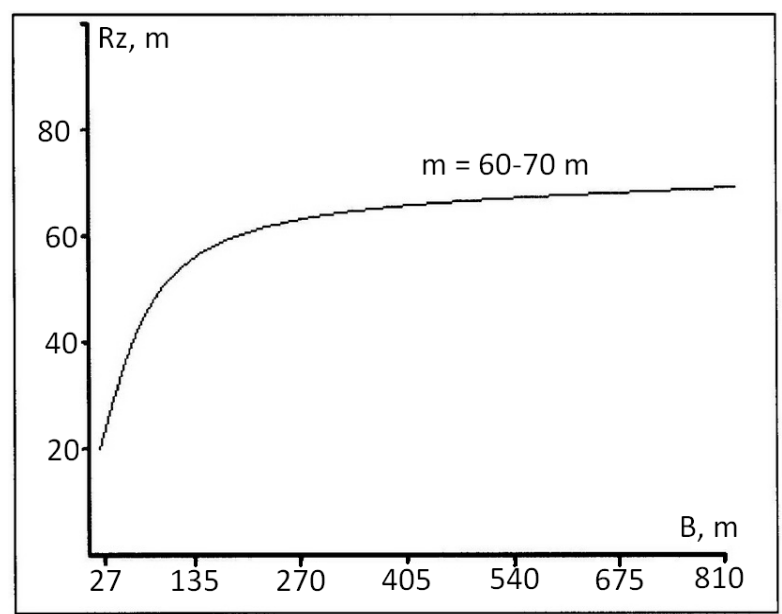

Figure 7 Depth of the maximal stress concentration zone, Rz, beneath the extraction level against the width of the stoping front, B. In this case, the orebody is 60 to $70 \mathrm{~m}$ thick, $B=27$ 
$\mathrm{m}$-one block is under extraction in the level; $B=135 \mathrm{~m}$-five blocks are under extraction; $B=810$ m-thirty blocks are under extraction

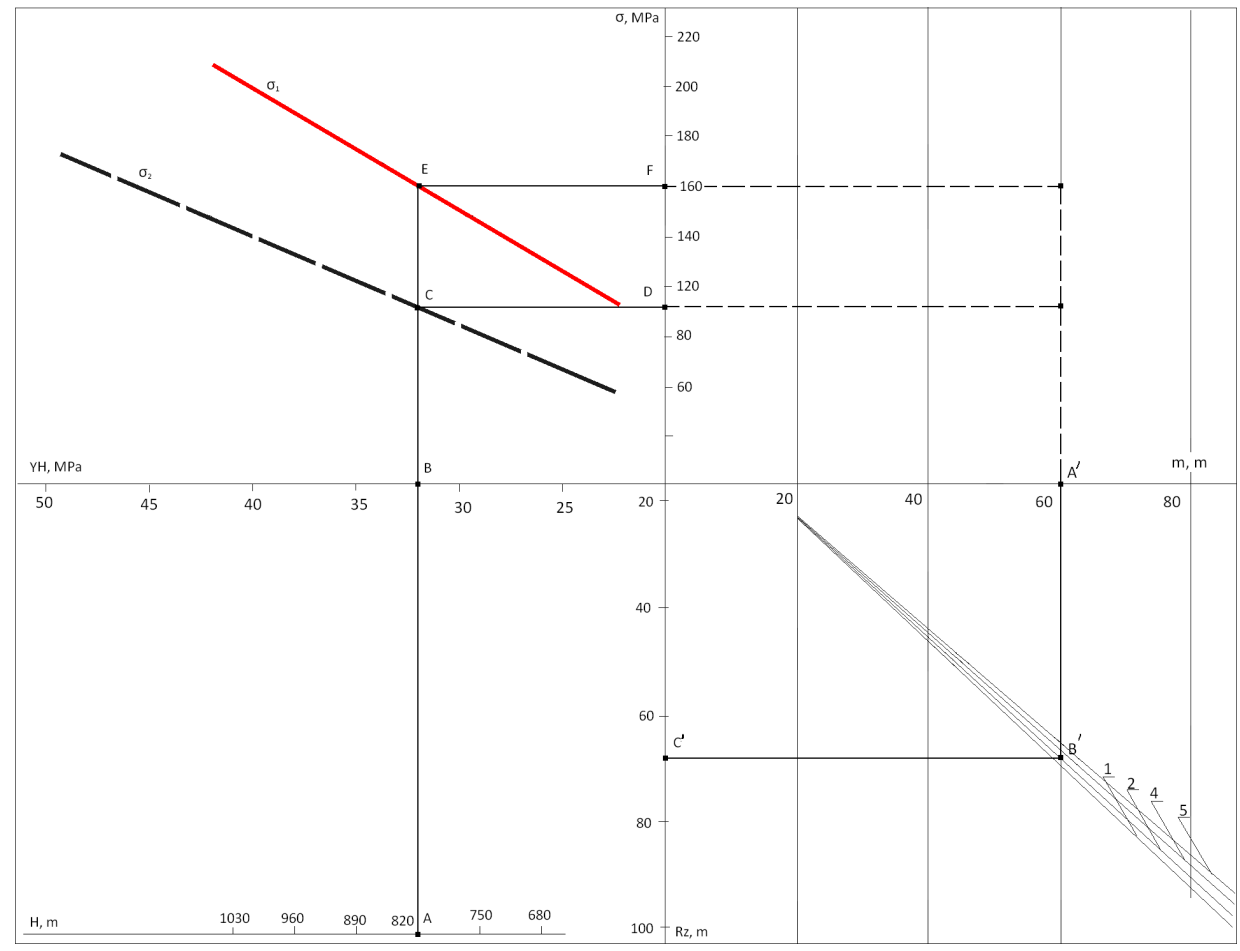

Figure 8 Nomogram for determining the occurrence depth of the maximal stress concentration, Rz.

Curves $1,2,3$, and 4 are plotted, respectively, for $\sigma_{\text {com }}=217.8 ; 181.8 ; 147.6$, and 114.3 $\mathrm{MPa}$. The domain ABCD: $\mathrm{H}=820 \mathrm{~m}, \gamma \mathrm{H}=32 \mathrm{MPa}, \sigma_{2}=112 \mathrm{MPa}$. The domain ABEF: $\mathrm{H}=820 \mathrm{~m}$, $\gamma \mathrm{H}=32 \mathrm{MPa}$,

$\sigma_{1}=160 \mathrm{MPa}$. A' B' $\mathrm{C}^{\prime}: \mathrm{m}=60 \mathrm{~m}, \sigma_{\text {com }}=147.6 \mathrm{MPa}, \mathrm{Rz}=69.6 \mathrm{~m}$

Figure 8 presents the developed nomogram intended to assess the stress concentration zone occurrence $\mathrm{Rz}$ versus the direction of the maximal horizontal stresses (across the strike is $\sigma_{1}$ and along the strike is $\sigma_{2}$, $\mathrm{MPa})$ in the extraction area, vertical stresses $(\gamma \mathrm{H}, \mathrm{MPa})$, orebody thickness $(T, m)$, mining depth $(\mathrm{H}, \mathrm{m})$, and the ultimate compression of rocks $\left(\sigma_{\mathrm{com}}, \mathrm{MPa}\right)$.

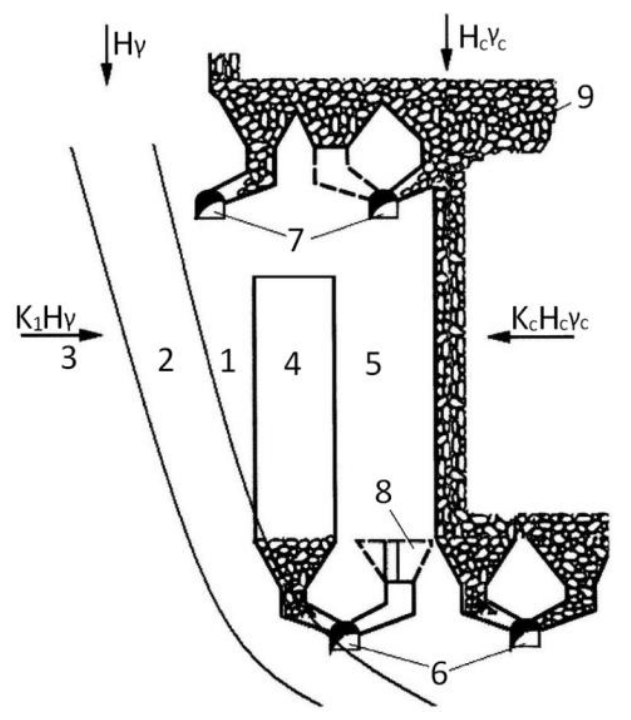

Figure 9 Stress-strain state of rocks in the course of mining with block caving. 1-post-limit stress state area; 2-limit stress state area; 3-elastic stress state area; 4- "balance chamber" (a chamber specially driven on a level or a sublevel to be caved, is intended to accommodate the expanded volume of caved rocks); 5 -pillar between blocks; 6-crossdrifts on 
the lower level; 7-crossdrifts on the higher level; 8-ore drawing outlets; 9-caved rocks; $\mathrm{H}$-mining depth, $\mathrm{m} ; \mathrm{r}$-specific weight of ore, $\mathrm{t} / \mathrm{m}^{3} ; \mathrm{H}_{\mathrm{c}}-$ height of caved rocks, $\mathrm{m} ; \gamma_{\mathrm{c}}-$ specific weight of caved rocks, $t / \mathrm{m}^{3}$;

$\mathrm{K}_{1}$-stress concentration coefficient in orebody (across the strike); $\mathrm{K}_{\mathrm{c}}$-stress concentration coefficient in caved rocks

The concentrated stresses have an effect on the entire area between the host rocks and the extracted ore block. The highest stresses are observed in the rock mass that is in the limit stress state due to mining operations, and stresses in these areas approach the value of the ultimate strength of rocks or even exceed it (Figure 9).
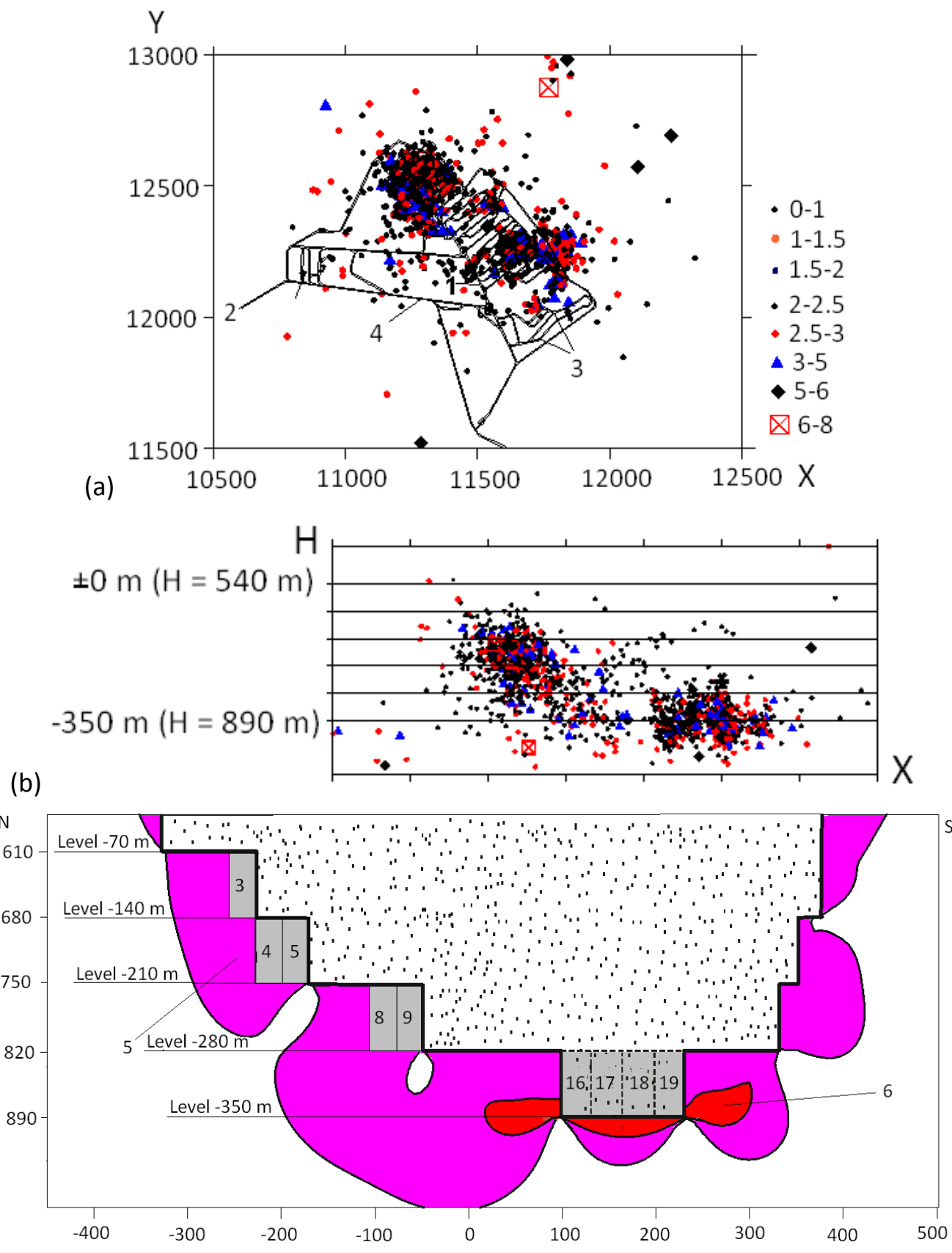

Figure 10 Induced seismic events and inelastic strain zones in one of mine districts in the Tashtagol Mine (Kuzbass) during large-scale blasting (data of 2010). Figures (a) and (b) show the seismic event concentrations on Level $-280 \mathrm{~m}$ in horizontal and vertical planes. Figure (c) shows the inelastic strain zones. Blasting was carried out in Block No. 19 on Level - $350 \mathrm{~m}$. H-depth from the daylight surface 
The post-limit stress state is induced in rocks by the mining operations and due to the natural stress state. High intensity displacements, deformations and seismic events take place in the post-limit stress areas. Numerical modelling with the Mohr-Coulomb failure criterion showed that the induced seismic events concentrate in the zones of inelastic strains as illustrated in Figure 10 (Bulychev, 1994; Baryshnikov and Gakhova, 2009).

The numerical modelling assumed that, due to structural weakening, the rock cohesion, $\mathrm{C}$, varies from 0.5-10 MPa. The inelastic strain zones in Figure 10 have been determined for shearing stress $\sigma_{s}$ comparable with the cohesion, i.e. $\sigma_{s} \geq 0.5 \mathrm{MPa}$ in soft rocks and $\sigma_{s} \geq 10 \mathrm{MPa}$ in hard rocks.

As extraction advances toward the centre of the orebody, the zones of the high density seismic events gradually move toward the edge of the orebody and the energies of the seismic events increase (Figure 11).

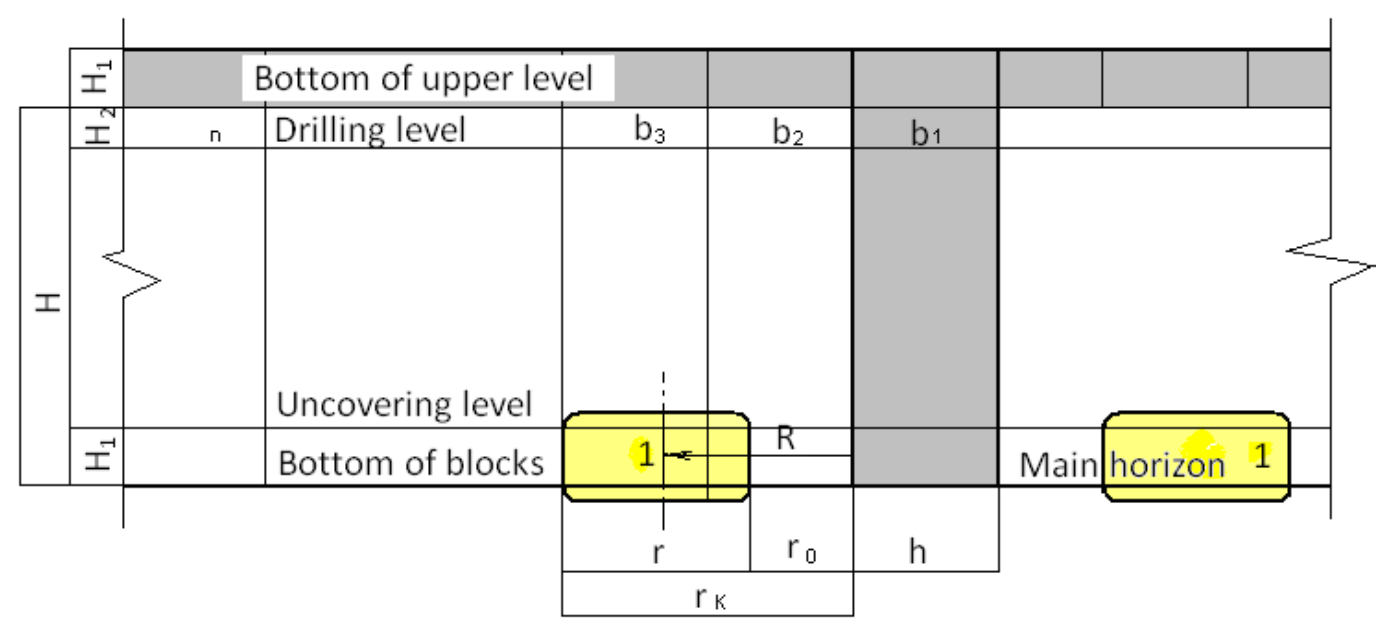

Figure 11 Zones of high density seismic events (indicated with 1). $b_{1}$-uncovering block on a level; $b_{2}-b_{n}-b$ locks under extraction; $h$-width of $b_{1}$; $R$-distance between the mined-out void and the centre of the high density seismic events zone; $r$-width of the high-density seismic zone; $r_{0}$ and $r_{k}$-boundaries of this zone; $H$-height of the level; $H_{1}$-height of the bottom of block; $\mathrm{H}_{2}$-height of the drilling level

The boundaries $r_{0}$ and $r_{k}$ of the zone of high density seismicity in the course of extraction advance from the centre toward the periphery of the orebody and are calculated from the expression:

$$
\left\{\mathrm{r}_{0} ; \mathrm{r}_{\mathrm{k}}\right\}=\{(\mathrm{r}+\mathrm{h}(\mathrm{n}-1.67)) ;(\mathrm{r}+\mathrm{h}(\mathrm{n}-0.33))\}
$$

where $r_{0}$ is the distance between the mined-out void and the near (relative to the goaf) boundary of the high density seismic zone, $\mathrm{m} ; \mathrm{r}_{\mathrm{k}}$ is the distance between the mined-out void and the distant (relative to the goaf) boundary of the high density seismic zone, $m$; $r$ is the width of the high density seismic zone, $m$; $h$ is width of an extraction block, $m ; n$ is the number of the extraction block ( $n=1$ is the first uncovering block on a level).

The distance between the mined-out void and the centre of the high density seismic zone, $\mathrm{R}$, is calculated from:

$$
\mathrm{R}=\mathrm{h}(\mathrm{n}+0.33)
$$

It has been found that large-scale blasting produces seismic events with energies from $10^{5}$ to $10^{8} \mathrm{~J}$ at the bottom of the extraction blocks, and with energies from $10^{2}$ to $10^{4} \mathrm{~J}$ in the roof and floor of the mined-out void. The stress concentration zones are traced at a distance of $100 \mathrm{~m}$ from the mined-out void, in the walls and bottom of the extraction block, and at a distance of $150 \mathrm{~m}$ from the mined-out void, in the roof of the extraction block. 
Based on these findings, the authors have developed some recommendations, including a decrease in height for levels and a height increase to avoid the main horizon and cutting workings to occur in the zones of high horizontal stress concentration. In addition, it becomes possible to install different kinds of supports in mine workings in the favourable time determined by the zones of high density seismic events.

\section{Conclusions}

When the height of a mined-out void is being increased and lateral stress is increased, the zone of the maximum stresses shifts towards the bottom of the void and the concentration factor of the horizontal stress increases. The stress concentration factor changes with distance from the mined-out void.

In the course of the top-to-bottom extraction of an iron orebody in West Siberia, the authors found that stress concentration areas and seismic events at the bottom of the extracted level-with regards to the orebody thickness, internal friction angle and cohesion of rocks-is illustrated by Equation (1).

Seismic events occur in the inelastic strain zones.

As extraction advances towards the orebody centre, the high density seismic zone gradually moves to the sides of the orebody and the energy of the events in these zones rises.

\section{References}

Baryshnikov, V.D. and Gakhova, L.N. (2009) Geomechanical conditions of kimberlite extraction in terms of Internatsionalnaya kimberlite pipe, in Journal of Mining Science, Vol. 45(3), pp. 137-145.

Bulychev, N.S. (1994) Mechanics of Underground Structures (in Russian), Moscow, Nedra, 382 p.

Eremenko, A.A., Eremenko, V.A. and Gaidin, A.P. (2008) Improved Geotechnology for Rockburst-Hazardous Iron Ore Mining Affected by Natural and Human-Induced Environment (in Russian), Novosibirsk, Nauka, $250 \mathrm{p}$.

Petukhov, I.M. and Batugina, I.M. (1999) The Earth's Interior Geodynamics (in Russian), Moscow, Nedra, 288 p.

Petukhov, I.M. and Zaprygaev, A.P. (1975) Rock stress assessment by core disking and drillings (in Russian), in The VNIMI Collected Works, No. 96.

Safe Mining Guide (1991) Safe Mining Guide for Rockburst-Hazardous Iron Orebodies in Gornaya Shoria (in Russian), Novokuznetsk, VostNIGRI, $90 \mathrm{p}$. 